Technical Note

\title{
Isolation and characterization of plant growth-promoting rhizobacteria and their effects on phytoremediation of petroleum-contaminated saline-alkali soil
}

\author{
Wuxing Liu ${ }^{\mathrm{a}, *}$, Jinyu Hou ${ }^{\mathrm{a}, \mathrm{b}}$, Qingling Wang ${ }^{\mathrm{a}}$, Linlin Ding ${ }^{\mathrm{a}}$, Yongming Luo ${ }^{\mathrm{a}, \mathrm{c}}$ \\ ${ }^{a}$ Key Laboratory of Soil Environment and Pollution Remediation, Institute of Soil Science, Chinese Academy of Sciences, Nanjing 210008, China \\ ${ }^{\mathrm{b}}$ University of Chinese Academy of Sciences, Beijing 100049, China \\ ${ }^{\mathrm{C}}$ Institute of Coastal Zone Research, Chinese Academy of Sciences, Yantai 264003, China
}

\section{H I G H L I G H T S}

- 115 PGPR strains were isolated from petroleum-contaminated saline-alkaline soils.

- Klebsiella sp. D5A displayed the highest plant-growth-promoting activity.

- D5A grew well on the LB medium containing 9\% $\mathrm{NaCl}$ and at $\mathrm{pH} 4-10$.

- Inoculation of D5A promoted phytoremediation of petroleum-contaminated soils.

\section{A R T I C L E I N F O}

\section{Article history:}

Received 7 April 2014

Received in revised form 3 July 2014

Accepted 4 July 2014

Handling Editor: O. Hao

\section{Keywords:}

PGPR

Klebsiella sp.

Soil contamination

Salinity

Alkalinity

\begin{abstract}
A B S T R A C T
This study aimed to isolate promising halotolerant and alkalotolerant plant growth-promoting rhizobacteria and to study their effects on the growth of tall fescue and phytodegradation efficiency in a petroleum-contaminated saline-alkaline soil. A total of 115 PGPR strains were isolated from the rhizosphere of tall fescue grown in petroleum-contaminated saline-alkaline soils. Of these, 5 strains indicating 1aminocyclopropane-l-carboxylic acid deaminase activity $>1.0 \mathrm{M} \alpha-\mathrm{KB} \mathrm{mg}^{-1} \mathrm{~h}^{-1}$ were selected for further studies. The isolate D5A presented the highest plant-growth-promoting activity and was identified as Klebsiella sp. It grew well on the Luria-Bertani medium containing $9 \% \mathrm{NaCl}$ and at a pH range of 4-10. A pot experiment was then conducted to study the effect of isolates on phytoremediation. The results showed that inoculation of D5A promoted tall fescue growth and enhanced remediation efficiency in petroleum-contaminated saline-alkaline soil.
\end{abstract}

(c) 2014 Elsevier Ltd. All rights reserved.

\section{Introduction}

Contamination of soil environment by petroleum hydrocarbons is becoming prevalent across the globe. A number of methods have been used to clean up the petroleum contaminated soils, but most of them are costly and difficult to get optimum results (Liu et al., 2010a,b). Bioremediation is an appealing and cost-effective approach to cleaning up this type of contaminants. There are many approaches of bioremediation including phytoremediation, land farming, slurry bioreactor treatment and composting. Among bioremediation methods, phytoremediation is a green technology that uses plants to remediate contaminated soils. Different from phyto-

\footnotetext{
* Corresponding author. Tel.: +86 25 86881842; fax: +86 2586881126 .

E-mail address: liuwuxin@issas.ac.cn (W. Liu).
}

remediation of heavy metals through plant uptake, phytoremediation of petroleum-contaminated soils relies on plant root exudation to create a biologically active soil region (i.e. the rhizosphere) that enhances contaminant bioavailability and encourages microbial degradation (Mohsen et al., 2010; Glick and Stearns, 2011).

Previous studies have shown that tall fescue (Testuca arundinacea $\mathrm{L}$.), a perennial species with a highly branched fine fibrous root system, could significantly increase the efficiency of hydrocarbon degradation in the soil (Huang et al., 2005; Gerhardt et al., 2009; Gurska et al., 2009; Liu et al., 2010a,b). It has also been reported hydrocarbon-degraders are able to aggressively colonize the root surface following root exudation. So the number of hydrocarbondegraders in the rhizosphere is generally higher than that in the bulk soil (Sumia et al., 2013). Clearly, extensive root growth is a 
prerequisite of maximizing the effectiveness of phytoremediation processes. However, most areas of oilfields such as Dagang, Shengli and Daqing Oilfields in China are located in saline-alkaline regions. The biomass accumulation and root growth of tall fescue can be severely affected by soil saline-alkaline stresses which consequently decrease the efficiency of phytoremediation.

Plant growth-promoting rhizobacteria (PGPR) are nonpathogenic beneficial soil rhizobacteria which play a key role in plant health and nutrition by a number of mechanisms. These include the synthesis of siderophores that can solubilize iron in the soil and make it available to the plant, the production of phytohormones, especially indole-3-acetic acid (IAA), and the presence of the enzyme 1-aminocyclopropane-l-carboxylic acid (ACC) deaminase that hydrolyzes ACC, the immediate precursor of the phytohormone ethylene (Glick et al., 1997). Earlier studies indicated that bacteria having plant-growth-promoting (PGP) activity could reduce the level of ethylene and result in better growth of plants under various stress conditions such as salinity, heavy metal toxicity and pathogen attack (Bal et al., 2013). Therefore, the application of PGPR is a promising approach to alleviating saline-alkaline stress on plants and improves the efficiency of phytoremediation in petroleum-contaminated soils.

Because soils of some oilfields located at saline-alkaline sites are natural habitats of haloalkaliphilic bacteria, isolation and utilization of PGPR from such natural habitats could prove to be beneficial for mitigating the saline-alkaline stress to the plants growing in such an environment. Though earlier work has involved isolation of salt-tolerant rhizobacteria from halophytic environments, little is known about their tolerance to alkaline environments where the contaminated soils have high $\mathrm{pH}$ (Qadir and Schubert, 2002).

The objectives of the present study were: (1) to isolate and characterize efficient ACC deaminase producing PGPR from the rhizosphere of tall fescue grown in saline-alkali soils, (2) to evaluate other PGP activities of the most promising ACC deaminase producing isolates under various saline-alkaline stresses, and (3) to study the effect of the selected isolates on tall fescue growth and phytoremediation of a petroleum-contaminated saline-alkaline soil.

\section{Materials and methods}

\subsection{Media and soil}

The compositions of Pseudomonas Agar F (PAF), Dworkin-Foster (DF) and tryptic soy broth media used to isolate and grow PGPR were based on Penrose and Glick (2003). The medium I comprised $\left(\mathrm{g} \mathrm{L}^{-1}\right) 10 \mathrm{~g}$ tryptone, $5 \mathrm{~g}$ yeast extract and $3 \mathrm{~g} \mathrm{NaCl}$ was used to study the effect of alkalinity stress on the growth of strain D5A.

Rhizospheric soil used for isolating PGPR were randomly collected from the roots of tall fescue in the top $15 \mathrm{~cm}$ depth at oil contaminated soil from Dagang and Shengli oilfields of China. The petroleum-contaminated soil used for phytoremediation was collected from Shengli oilfield, Shandong, China. The soil had the following basic properties: pH 9.7 (1: 2.5 water), electrical conductivity (1:5) $404 \mu \mathrm{S} \mathrm{cm}^{-1}$; cation exchange capacity $4.94 \mathrm{cmol} \mathrm{kg}^{-1}$; organic matter $4.26 \mathrm{~g} \mathrm{~kg}^{-1}$; hydrolyzable nitrogen $23.7 \mathrm{mg} \mathrm{kg}^{-1}$; $\mathrm{NaHCO}_{3}$-extractable $\mathrm{P} 8.6 \mathrm{mg} \mathrm{kg}^{-1}$ and $\mathrm{NH}_{4} \mathrm{OAc}$-extractable $\mathrm{K}$ $176 \mathrm{mg} \mathrm{kg}^{-1}$. TPH (total petroleum hydrocarbon) concentration of soil is $16920 \mathrm{mg} \mathrm{kg}^{-1}$. The petroleum fractions of C12-C16, C16C21 and >C21 were 441,2720 and $13760 \mathrm{mg} \mathrm{kg}^{-1}$, respectively, but fraction of $<\mathrm{C} 12$ was not detected. Soil properties were measured according to Lu (1999) and TPH and petroleum fractions based on the method of Yang et al. (2014).

\subsection{PGPR isolation}

PGPR with ACC deaminase activity were isolated according to the method of Penrose and Glick (2003). Briefly, an aliquot of $1 \mathrm{~g}$ soil was added to $50 \mathrm{~mL}$ sterile PAF medium in a $250-\mathrm{mL}$ flask and incubated aerobically at $21^{\circ} \mathrm{C}$ on a reciprocal shaker at $200 \mathrm{rpm}$ for $24 \mathrm{~h}$. Then, one $\mathrm{mL}$ aliquot was removed from the growing culture, transferred to $50 \mathrm{~mL}$ of sterile PAF medium and incubated in the same manner for $24 \mathrm{~h}$. Following these two incubations, the population of bacteria with ACC deaminase activity was enriched and the number of fungi in the culture was reduced. One $\mathrm{mL}$ aliquot was removed from the second culture and transferred to $50 \mathrm{~mL}$ sterile DF salts minimal medium. After incubation at $21^{\circ} \mathrm{C}$ on a reciprocal shaker at $200 \mathrm{rpm}$ for $24 \mathrm{~h}$, one $\mathrm{mL}$ aliquot was removed from this culture and transferred to $50 \mathrm{~mL}$ sterile DF salts minimal medium containing $3.0 \mathrm{mM} \mathrm{ACC}$ (instead of $\left.\left(\mathrm{NH}_{4}\right)_{2} \mathrm{SO}_{4}\right)$ as the source of nitrogen, namely ADF medium, the culture was placed in a shaking water bath at $200 \mathrm{rpm}$ and grown at $21^{\circ} \mathrm{C}$ for $24 \mathrm{~h}$. Dilutions of this final culture were plated onto solid ADF salts minimal medium (2\% agar) and incubated for $48 \mathrm{~h}$ at $28^{\circ} \mathrm{C}$. Colonies of different morphologies were picked up and purified.

\subsection{ACC deaminase, phosphate solubilization, IAA and siderophore assay}

The ACC deaminase activity of cell-free extracts was measured based on the determination of $\alpha$-ketobutyrate $(\alpha-K B)$ resulting from ACC cleavage by ACC deaminase and enzyme activity was expressed as $M \alpha-K B g^{-1} h^{-1}$, as described in Liu et al. (2013). Siderophore secretion by the strains was detected by the improved method of Payne (1994). The strains were cultured in the modified sugar-aspartic acid medium and shaken at $150 \mathrm{rpm}$ at $30^{\circ} \mathrm{C}$ for $48 \mathrm{~h}$. After centrifugation, $1.5 \mathrm{~mL}$ of cell-free culture supernatant was mixed with $1.5 \mathrm{~mL}$ of chrome azurol sulfonate assay solution (Wolicka et al., 2009). After $1 \mathrm{~h}$, the absorbance (A) of the mixture is measured at $630 \mathrm{~nm}$. The non-inoculated supernatant used as a reference of which absorbance (Ar) was determined by the above method. The quantitative index was the value of $\mathrm{A} / \mathrm{Ar}$ which was inversely related to siderophore production. General reference standards: A/Ar 0-0.2, + ++ ++; 0.2-0.4, + ++ +; 0.4-0.6, + ++; $0.6-0.8,++; 0.8-1.0,+$.

Production of IAA was measured according to the Salkowski colorimetric assay (Glickmann and Dessaux, 1995). The phosphate solubilization activity of the isolates was analyzed according to Sundara-Rao and Sinha (1963).

\subsection{PGP ability using tall fescue under salt stress}

Uniform seeds of tall fescue were sterilized in $70 \%$ ethanol for $2 \mathrm{~min}$ and in $1 \%$ sodium hypochlorite for $10 \mathrm{~min}$ and then rinsed twice with sterile water. The sterilized seeds were immersed for $6 \mathrm{~h}$ in the isolate suspension $\left(\mathrm{OD}_{600 \mathrm{~nm}}=0.5\right)$ or in $0.03 \mathrm{M} \mathrm{MgSO}_{4}$ solution as the control. Twenty pretreated seeds were grown in a Petri dish containing two layers of Whatman No. 1 filter paper, moistened with different concentrations of $\mathrm{NaCl}$ solution (0-9\%). The Petri dishes were placed in biochemistry incubators at $28^{\circ} \mathrm{C}$. Seed germination rate, shoot height and root length of seedlings were recorded after 2 weeks. All the operations were done under sterilized conditions and care was taken to avoid contamination during growth and handling of the plants.

\subsection{Effects of $\mathrm{pH}$ and salinity on the growth and IAA production of strain D5A}

The LB medium containing $0.5 \mathrm{mg} \mathrm{L}^{-1}$ of tryptophan was used to study effects of $\mathrm{pH}$ and salinity on the growth and IAA produc- 
tion of strain Klebsiella sp. D5A. The medium (100 mL) with different concentrations of $\mathrm{NaCl}(0-21 \%)$ was prepared to test salt tolerance of the bacterial isolate. To test $\mathrm{pH}$ response, the $\mathrm{pH}$ of $\mathrm{LB}$ medium was adjusted to 9 different levels ( $\mathrm{pH}$ 3-11) using $1 \mathrm{M}$ $\mathrm{HCl}$ or $\mathrm{NaOH}$. Flasks with salt and $\mathrm{pH}$ treatments were inoculated with suspension of Klebsiella sp. D5A cultured overnight in a shaker at $28{ }^{\circ} \mathrm{C}, 200 \mathrm{rpm}$ for $24 \mathrm{~h}$. In all cases, the concentration of IAA and OD value reflecting the biomass in the medium were determined directly.

\subsection{Effect of different levels of $\mathrm{Na}_{2} \mathrm{CO}_{3}$ and $\mathrm{NaHCO}_{3}$ stress on the growth of strain $D 5 A$}

The medium I ( $5 \mathrm{~mL}$ ) with different concentrations of (0$300 \mathrm{mM}) \mathrm{Na}_{2} \mathrm{CO}_{3}$ and $\mathrm{NaHCO}_{3}$ was used to study the alkalinity stress on the growth of strain D5A, pH was also tested at the same time. Inoculated $50 \mu \mathrm{L}$ suspension of Klebsiella sp. D5A into the culture, $28^{\circ} \mathrm{C}, 160 \mathrm{rpm}$. The $\mathrm{OD}_{600 \mathrm{~nm}}$ was determined after shaking $48 \mathrm{~h}$.

\subsection{Physiological characterization and $16 S$ rRNA gene sequencing of strain D5A}

Morphological properties of Klebsiella sp. D5A were examined by light and transmission electron microscopy. 16S rDNA sequences were amplified from chromosomal DNA by PCR using universal oligonucleotide primers and sequenced as described by Lee et al. (2010). The sequence was then compared to the 16S rDNA sequence in the GenBank database by BLAST. Multiple sequence alignment was done using CLUSTAL X software and a phylogenetic tree was constructed by the neighbor-joining method using MEGA (Version 4.1) software. The confidence level of each branch (1000 repeats) was tested by bootstrap analysis. The $16 \mathrm{~S}$ rDNA sequence of isolate D5A was deposited in the GenBank database with accession numbers JQ227465.

\subsection{PGPR assisted phytoremediation of petroleum contaminated soil}

To evaluate the effect of the isolate Klebsiella sp. D5A on the growth of tall fescue and petroleum-removal efficiency in the saline-alkaline soil, a pot experiment was conducted in growth chambers. The experiment consisted of 3 treatments in 4 replicates. The treatments were (1) no-plant control, (2) tall fescue and (3) tall fescue inoculated with Klebsiella sp. D5A (tall fescue + D5A). Plastic pots were filled with $2.0 \mathrm{~kg}$ air-dry soil, and water content of the soil was maintained at about $80 \%$ field capacity during the experimental period. Inorganic nutrients $\left(\mathrm{NH}_{4}\right)_{2} \mathrm{SO}_{4}$ and $\mathrm{K}_{2} \mathrm{HPO}_{4}$ was added to all treatments to give a final rates of $250 \mathrm{mg} \mathrm{N} \mathrm{kg}^{-1}$ and $100 \mathrm{mg} \mathrm{P} \mathrm{kg}^{-1}$. Other nutrients in the soil were at the adequate range and thus were not added.

Uniform seeds were surface sterilized by immersing in $0.3 \%$ sodium hypochlorite for $5 \mathrm{~min}$ and rinsing with sterilized distilled water. An aliquot of 50 seeds were then sown in each pot of the planted treatments. For the tall fescue + D5A treatment, the strain D5A at the exponential growth phase in the LB medium were collected by centrifugation at $9000 \mathrm{rpm}$ for $15 \mathrm{~min}$ at $4{ }^{\circ} \mathrm{C}$, washed with sterile distilled water and centrifuged. The inoculum was prepared by re-suspending pelleted cells in sterile distilled water and bacterial suspension $\left(10 \mathrm{~mL} \mathrm{pot}^{-1}\right)$ was mixed with the soil before sowing seeds. Plants were harvested at $120 \mathrm{~d}$.

\subsection{Plant analysis}

Plants were harvested on day 120 . Plant biomass was determined after oven dried at $70^{\circ} \mathrm{C}$ for $48 \mathrm{~h}$. RA was determined using the triphenyl tetrazolium chloride method (Clemensson-Lindell
1994). The root activity was expressed as $\mu \mathrm{g}$ triphenyl tetrazolium formazane $\mathrm{g}^{-1} \mathrm{~h}^{-1}$ on a fresh-weight basis.

Chlorophyll concentration was measured according to Moran and Porath (1980). Two hundred milligrams of plant leaves were cut into $0.5 \mathrm{~cm}$ segments and incubated in $80 \%$ acetone for $24 \mathrm{~h}$, at $4{ }^{\circ} \mathrm{C}$, in the dark. Absorbance of the solutions was measured with a spectrophotometer at 645 and $663 \mathrm{~nm}$. Chlorophyll concentrations $\left(\mathrm{mg} \mathrm{mL}^{-1}\right)$ were calculated using the following equations (Moran and Porath, 1980):

Chlorophyll $=\left[8.02 \times A_{633}\right]-\left[20.2 \times A_{645}\right]$

\subsection{Statistical analysis}

All experiments were conducted in four replicates or otherwise specified. The data collected were analyzed statistically using SPSS 16.0 software. Duncan's multiple range tests were used to compare the means of the treatments, variability in the data was expressed as the standard deviation, and $P<0.05$ was considered to be statistically significant.

\section{Results}

\subsection{PGP features of the isolates}

A total of 115 rhizobacteria which could use ACC as a sole nitrogen source on the ADF plate were isolated from five rhizosphere soil samples and tested qualitatively for ACC deaminase activity. Of these, 5 strains shown ACC deaminase activity $>1.0 \mathrm{M} \alpha$ $\mathrm{KB} \mathrm{mg} \mathrm{m}^{-1} \mathrm{~h}^{-1}$ were selected for further study. The potential PGP characters of the selected strains were evaluated in vitro based on phosphate solubilization activity, and production of siderophore and phytohormone (IAA) in chemically defined media. IAA production was observed in 5 isolates in the range $8-112 \mathrm{mg} \mathrm{L}^{-1}$, phosphate solubilization activity in the range $31-131 \mathrm{mg} \mathrm{L}^{-1}$ and all 5 isolates produced siderophore. Apart from siderophore production, isolate D5A exhibited the highest level in ACC deaminase activity, phosphate solubilization and IAA production (Table 1).

\subsection{PGP ability of isolates on tall fescue seedlings under salt stress}

The effects of the isolates on seed germination rate, root length and shoot height of tall fescue under different salt stresses were summarized in Table 2. Without inoculation, increasing salinity level decreased the germination rate, shoot height and root length with root growth being most sensitive. The inoculation of PGPR isolates increased root length and shoot height when $\mathrm{NaCl}$ was added. Among the isolates, D5A showed the best plant growth-promoting ability. The inoculation of D5A increased germination rate, root length and shoot height by $6 \%, 12 \%$ and $3 \%$ under no $\mathrm{NaCl}, 14 \%$, $17 \%$ and $11 \%$ under $3 \mathrm{~g} \mathrm{~kg}^{-1} \mathrm{NaCl}, 13 \%, 43 \%$ and $29 \%$ under $6 \mathrm{~g} \mathrm{~kg}^{-1}$ $\mathrm{NaCl}$, and $109 \%, 29 \%$ and $54 \%$ under $9 \mathrm{~g} \mathrm{~kg}^{-1} \mathrm{NaCl}$, respectively (Table 2).

\subsection{Morphological characteristics and phylogenetic position of isolate D5A}

The colonies of strain D5A are translucent, smooth and convex on solid ADF plates. Cells are Gram-negative, rod-shaped (0.7$0.9 \mu \mathrm{m}$ thick and $1.8-3.0 \mu \mathrm{m}$ long) (figure not shown). Physiological and biochemical tests indicated D5A to be aerobic, positive for starch utilization, glucose fermenters, indole production, VogesProskauer test, but negative for gelatin hydrolysis and citrate positive. 16S rRNA gene sequences (GenBank accession No. JQ227465) of D5A were also used to identify the strain. In the phylogenetic 
Table 1

Traits of bacteria containing ACC deaminases isolated from the petroleum-contaminant soil.

\begin{tabular}{|c|c|c|c|c|}
\hline Strains & ACC deaminase activity ( $\mathrm{M} \alpha-\mathrm{KB} \mathrm{mg}^{-1} \mathrm{~h}^{-1}$ ) & IAA $\left(\mathrm{mg} \mathrm{L}^{-1}\right)$ & Phosphate solubilization $\left(\mathrm{mg} \mathrm{L}^{-1}\right)$ & Siderophore production (A/Ar) \\
\hline $\mathrm{D} 1 \mathrm{~A}$ & $2.40 \pm 0.35 b$ & $110 \pm 6 a$ & $31 \pm 2 c$ & + \\
\hline D5A & $5.04 \pm 0.12 \mathrm{a}$ & $112 \pm 9 a$ & $131 \pm 5 a$ & + \\
\hline S1C & $2.28 \pm 0.17 b$ & $8 \pm 1 d$ & $83 \pm 6 b$ & ++++ \\
\hline W2 & $2.22 \pm 0.09 \mathrm{~b}$ & $90 \pm 4 b$ & $34 \pm 2 c$ & + \\
\hline W50 & $1.20 \pm 0.09 c$ & $62 \pm 4 c$ & $36 \pm 3 c$ & + \\
\hline
\end{tabular}

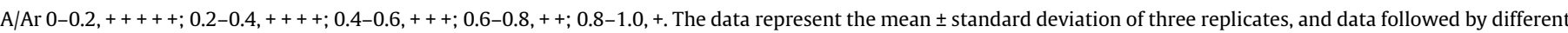
letters in the same row indicate a significant difference at $p<0.05$ according to Duncan's multiple range tests.

Table 2

Effects of PGPR on the growth of tall fescue seedlings grown for $10 \mathrm{~d}$ in the Petri dish containing $0-9 \mathrm{~g} \mathrm{~kg}^{-1} \mathrm{NaCl}_{\text {. }}$

\begin{tabular}{|c|c|c|c|c|c|c|c|c|c|c|c|c|}
\hline & \multicolumn{4}{|c|}{ Germination rate (\%) } & \multicolumn{4}{|c|}{ Shoot height $(\mathrm{cm})$} & \multicolumn{4}{|c|}{ Root length (cm) } \\
\hline & 0 & 3 & 6 & 9 & 0 & 3 & 6 & 9 & 0 & 3 & 6 & 9 \\
\hline Control & $92 \pm 6 a$ & $83 \pm 3 b c$ & $78 \pm 29 b c$ & $35 \pm 0 b$ & $6.7 \pm 0.2 c$ & $6.1 \pm 0.1 c$ & $3.7 \pm 0.4 \mathrm{c}$ & $2.8 \pm 0.2 b$ & $3.6 \pm 0.2 \mathrm{a}$ & $2.9 \pm 0.1 \mathrm{bc}$ & $1.1 \pm 0.1 b c$ & $0.9 \pm 0.1 c$ \\
\hline D1A & $95 \pm 5 a$ & $92 \pm 6 a b$ & $92 \pm 10 a$ & $43 \pm 6 c$ & $7.2 \pm 0.1 \mathrm{ab}$ & $6.8 \pm 0.1 b$ & $5.6 \pm 0.3 a$ & $3.1 \pm 0.1 \mathrm{ab}$ & $3.6 \pm 0.1 \mathrm{a}$ & $3.1 \pm 0.1 \mathrm{ab}$ & $1.4 \pm 0.5 b$ & $1.1 \pm 0.1 b$ \\
\hline D5A & $97 \pm 3 a$ & $95 \pm 0 a$ & $88 \pm 13 b$ & $73 \pm 3 \mathrm{ba}$ & $7.5 \pm 0.1 \mathrm{a}$ & $7.1 \pm 0.1 \mathrm{a}$ & $5.2 \pm 1.2 \mathrm{ab}$ & $3.6 \pm 0.2 \mathrm{a}$ & $3.7 \pm 0.1 \mathrm{a}$ & $3.2 \pm 0.1 \mathrm{a}$ & $1.8 \pm 0.2 \mathrm{a}$ & $1.3 \pm 0.2 \mathrm{a}$ \\
\hline W50 & $95 \pm 5 a$ & $83 \pm 3 b c$ & $77 \pm 6 b c$ & $40 \pm 9 b c$ & $7.0 \pm 0.4 \mathrm{abc}$ & $6.8 \pm 0.1 b$ & $4.3 \pm 0.4 \mathrm{bc}$ & $2.9 \pm 0.7 b$ & $3.2 \pm 0.2 \mathrm{a}$ & $2.7 \pm 0.2 \mathrm{bc}$ & $1.3 \pm 0.2 b c$ & $1.1 \pm 0.1 b$ \\
\hline S1C & $93 \pm 8 a$ & $87 \pm 10$ abc & $47 \pm 8 d$ & $42 \pm 3 b$ & $7.0 \pm 0.3 \mathrm{bc}$ & $6.8 \pm 0.2 b$ & $3.1 \pm 0.4 \mathrm{c}$ & $2.8 \pm 0.2 b$ & $3.6 \pm 0.1 \mathrm{a}$ & $2.8 \pm 0.2 \mathrm{abc}$ & $1.0 \pm 0.1 c$ & $1.1 \pm 0 b$ \\
\hline W2 & $95 \pm 5 a$ & $80 \pm 5 a$ & $73 \pm 3 c$ & $32 \pm 3 c$ & $6.9 \pm 0.3 b c$ & $5.9 \pm 0.2 c$ & $4.2 \pm 0.8 \mathrm{bc}$ & $2.0 \pm 0.2 c$ & $3.6 \pm 0.1 \mathrm{a}$ & $2.4 \pm 0.1 c$ & $1.3 \pm 0.1 b c$ & $0.8 \pm 0.1 c$ \\
\hline
\end{tabular}

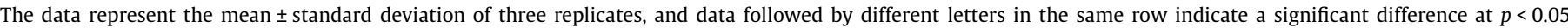
according to Duncan's multiple range tests.

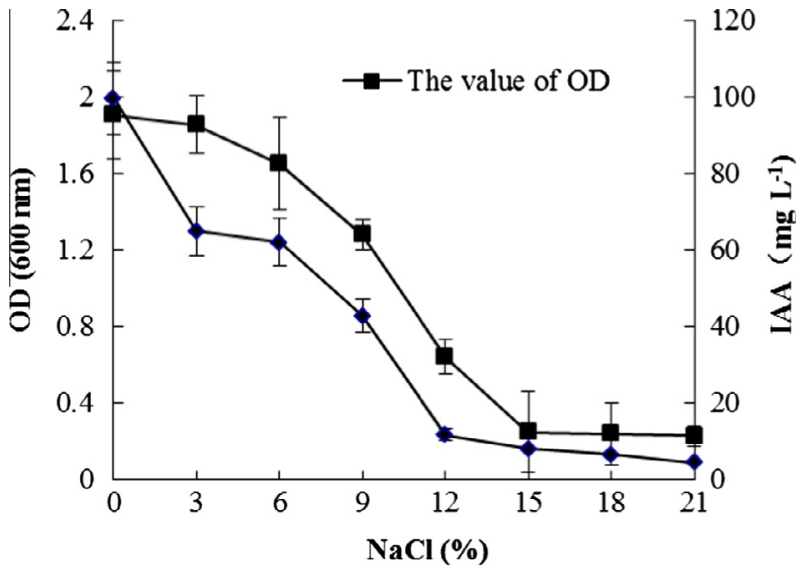

Fig. 1. The biomass and IAA production of D5A strains cultured in the LB medium with various salt concentrations. Error bars are \pm s.e. $(n=3)$.

tree (data not shown), the strain D5A in the Klebsiella branch exhibited highest (99.5\%) sequence similarity to Klebsiella variicola (HQ259961). This strain has been deposited in Chinese Culture Collection Management Committee General Microbiology Center (CGMCC) and the number of the strain is CGMCC No. 7248.

\subsection{Response of D5A to salinity and $\mathrm{pH}$}

The growth of strain $\mathrm{D} 5 \mathrm{~A}$, based on $\mathrm{OD}_{600 \mathrm{~nm}}$ values obtained at $24 \mathrm{~h}$, was not affected by $\mathrm{NaCl}$ up to $6 \%$ and only decreased by $33 \%$ at $9 \% \mathrm{NaCl}$ (Fig. 1), indicating that D5A was highly tolerant to salinity. IAA production was linearly suppressed with increasing salt content from $0.5 \%$ to $15 \%$. In general, both the growth and IAA production were not affected by $\mathrm{pH}$ between 4 and 10 (Fig. 2), suggesting that the strain could adapt to a wide range of $\mathrm{pH}$.

\subsection{Resistance of D5A to alkalinity stress}

The $\mathrm{OD}_{600 \mathrm{~nm}}$ value of strain D5A was hardly affected by $\mathrm{NaHCO}_{3}$ up to $100 \mathrm{mM}$ and then decreased when $\mathrm{NaHCO}_{3}$ concentration exceeded $100 \mathrm{mM}$. Nevertheless, the $\mathrm{OD}_{600 \mathrm{~nm}}$ value was still as

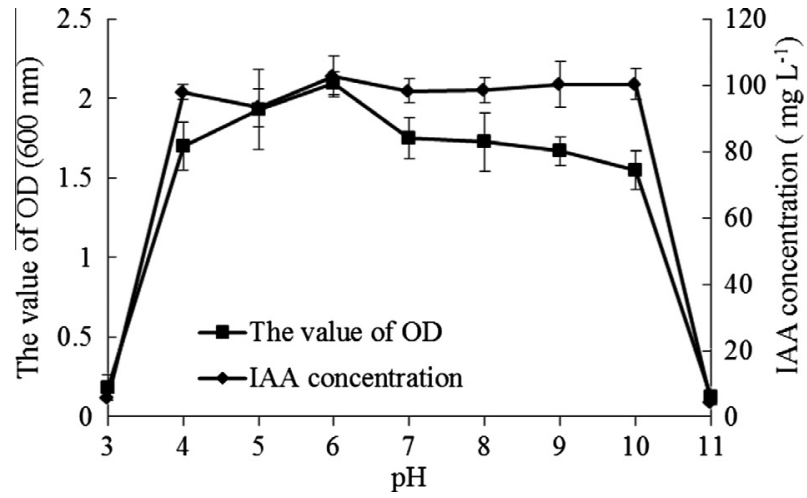

Fig. 2. The biomass and IAA production of D5A strains in the LB medium with different $\mathrm{pH}$. Error bars are \pm se $(n=3)$.

high as 1.03 even at $200 \mathrm{mM}$ ( $\mathrm{pH}$ 7.68). In comparison, the $\mathrm{OD}_{600 \mathrm{~nm}}$ value of strain D5A continuously declined with increasing $\mathrm{Na}_{2} \mathrm{CO}_{3}$ in the range of $0-50 \mathrm{mM}$. There was no obvious growth after exposure to $250 \mathrm{mM} \mathrm{NaHCO}$ ( $\mathrm{pH} 7.72$ ) or $50 \mathrm{mM} \mathrm{Na}_{2} \mathrm{CO}_{3}$ (pH 9.93). As for the $1: 1$ mixture of $\mathrm{NaHCO}_{3}$ and $\mathrm{Na}_{2} \mathrm{CO}_{3}$, the strain was virtually undetectable even at the concentration of $75 \mathrm{mM}$.

\subsection{Influence of D5A on plant growth and TPH removal}

The inoculation of D5A significantly improved seed germination, biomass production and chlorophyll contents in leaves of tall fescue grown in the petroleum-contaminated saline-alkaline soil (pH 9.7 and EC $404 \mu \mathrm{S} \mathrm{cm}^{-1}$ ). Shoot dry weight was almost 3 times greater in the inoculated than non-inoculated treatment by the end of the experiment (Table 3). The inoculation also increased root dry weight, RA and chlorophyll contents by $73 \%, 101 \%$ and $170 \%$, respectively.

The TPH contents in the soil after $120 \mathrm{~d}$ decreased by $42 \%, 50 \%$ and $66 \%$ in the non-plant control, tall fescue and tall fescue + D5A treatments, respectively. The content of TPH was significantly lower $(P<0.05)$ in two treatments with plants than the control, and the inoculation of D5A further decreased TPH contents. As is 
Table 3

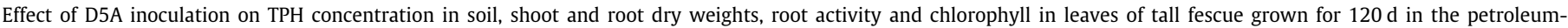
contaminated soil.

\begin{tabular}{|c|c|c|c|}
\hline & No-plant control & Tall Fescue & Tall Fescue+D5A \\
\hline TPH concentration $\left(\mathrm{mg} \mathrm{kg}^{-1}\right)$ & $9793 \pm 286 a$ & $8415 \pm 464 b$ & $5700 \pm 433 c$ \\
\hline$<\mathrm{C} 12$ concentration $\left(\mathrm{mg} \mathrm{kg}^{-1}\right)$ & ND & ND & ND \\
\hline C12-C16 concentration $\left(\mathrm{mg} \mathrm{kg}^{-1}\right)$ & $277 \pm 32 a$ & $195 \pm 10 b$ & $105 \pm 15 c$ \\
\hline C16-C21 concentration $\left(\mathrm{mg} \mathrm{kg}^{-1}\right)$ & $1307 \pm 53 a$ & $1145 \pm 128 b$ & $795 \pm 72 c$ \\
\hline$>\mathrm{C} 21$ concentration $\left(\mathrm{mg} \mathrm{kg}^{-1}\right)$ & $8209 \pm 210 a$ & $7075 \pm 330 b$ & $4800 \pm 346 c$ \\
\hline Shoot dry weight $\left(\mathrm{g} \mathrm{pot}^{-1}\right)$ & - & $0.91 \pm 0.11 b$ & $3.67 \pm 0.97 a$ \\
\hline Root dry weight $\left(\mathrm{g} \mathrm{pot}^{-1}\right)$ & - & $1.51 \pm 0.35 b$ & $2.61 \pm 0.25 a$ \\
\hline Chlorophyll contents ( $\mathrm{mg} \mathrm{g}^{-1}$ f. wt.) & - & $1.47 \pm 0.15 b$ & $3.97 \pm 0.28 a$ \\
\hline Root activity ( $\mu \mathrm{g} \mathrm{h}^{-1} \mathrm{~g}^{-1} \mathrm{f}$. wt.) & - & $721 \pm 73 b$ & $1446 \pm 47 a$ \\
\hline
\end{tabular}

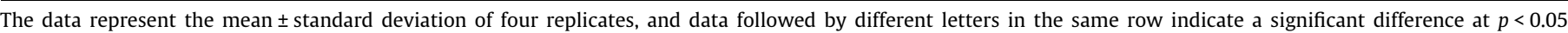
according to Duncan's multiple range tests. ND, not detectable; -, not applicable.

expected, the fraction below $\mathrm{C} 12$ was not detectable and over $80 \%$ of TPH were $>\mathrm{C} 21$ fractions in all treatments given the soil used in this experiment was contaminated for many years and the lighter fraction are easily removed by evaporation and degradation (Table 3).

\section{Discussion}

ACC deaminase, IAA and siderophore production, and phosphate solubilization are important contributors to plant growth (Glick 1995). Thus, these characters were used to isolate PGPR. Over one hundred rhizobacteria which could use ACC as a sole nitrogen source on the ADF plate were obtained and five most promising strains with higher activity of ACC deaminase were further evaluated for their ability to produce IAA and siderophores (Table 1). Among these, the isolated D5A showed high PGP activities and the best growth-promoting ability (Table 2).

On the basis of morphological, physiological, biochemical characteristics, phylogenetic position and genes sequences of $16 \mathrm{~S}$ rRNA, the isolated strain D5A was identified as Klebsiella sp. This study demonstrated that D5A was highly tolerant to extreme $\mathrm{pH}$, high salinity and high alkalinity, and thus has potential to develop as a PGPR inoculum for improving plant growth and TPH removal in highly saline-alkaline soils. The results showed that the isolate D5A was able to grow and produce a high amount of IAA even in the presence $9 \% \mathrm{NaCl}$ (Fig. 1). The isolate D5A was capable of producing a large amount of mucous and exopolysaccharides (data not shown) which bind cations including $\mathrm{Na}^{+}$and decrease the content of $\mathrm{Na}^{+}$available for plant uptake, thus helping alleviate salt stress in plants (Ashraf et al., 2004). Extreme pH values may be one of the major limiting factors for the presence of microorganisms in soils. D5A kept optimal growth and producing IAA at the $\mathrm{pH}$ range from 4 to 10 (Fig. 2). In contrast, common PGPR have a narrow range of optimal pH (Shrivastava, 2013). This indicates that the isolate could also be a strong candidate for the improvement of plant growth in highly alkaline or acidic soils. Compared with $\mathrm{Cl}^{-1}, \mathrm{HCO}_{3}^{-1}$ and $\mathrm{CO}_{3}^{-2}$ at same $\mathrm{pH}$ are more toxic for organisms. Unfortunately, the chemical properties of saline-alkaline soils are related tightly to the presence of $\mathrm{Na}_{2} \mathrm{CO}_{3}$ and $\mathrm{NaHCO}_{3}$ in the soil (Vorob'eva and Pankova, 2008). Although many studies have examined the $\mathrm{Na}_{2} \mathrm{CO}_{3}$ tolerance of plants, little is known about the resistance of bacterial strains to $\mathrm{Na}_{2} \mathrm{CO}_{3}$. In this study, Strain D5A could grow well in $25 \mathrm{mM} \mathrm{Na}_{2} \mathrm{CO}_{3}\left(\mathrm{OD}_{600 \mathrm{~nm}}=1.375\right)$ (Fig. 3) while plant growth could be seriously affected when the $\mathrm{Na}_{2} \mathrm{CO}_{3}$ concentration in soil solution reached $5 \mathrm{mM}$ (Lu et al., 2010). So D5A might be used to alleviate the saline-alkaline stress on plants and to improve the efficiency of phytoremediation in saline-alkali soils.

The degradation of most hydrocarbons is believed to enhance through a rhizosphere effect. Our present study showed that, as

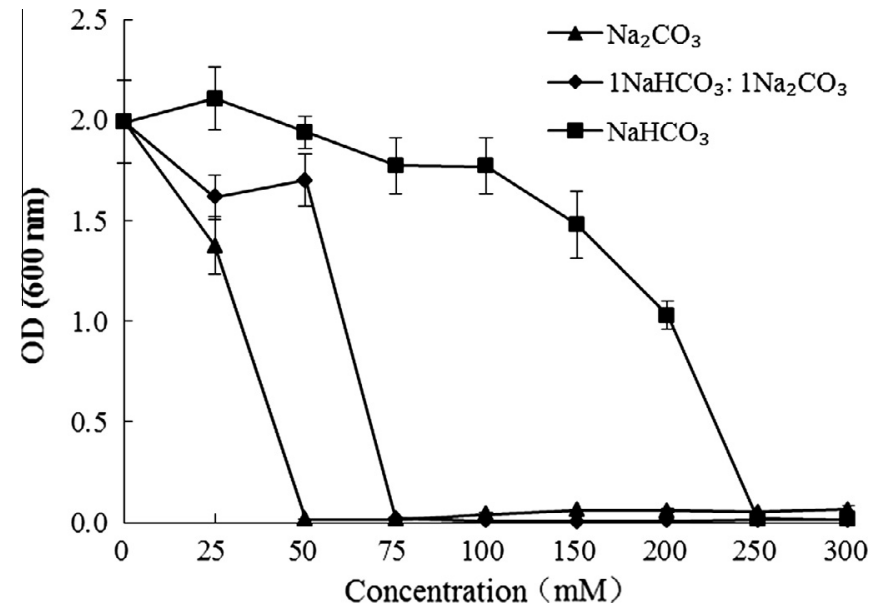

Fig. 3. Different concentration of $\mathrm{Na}_{2} \mathrm{CO}_{3}$ and $\mathrm{NaHCO}_{3}$. Error bars are $\pm \mathrm{se}(n=3)$.

expected, salt stress decreased shoot growth and root length of tall fescue. However, the inoculation of PGPR strains, especially D5A, improved all plant growth parameters in the salt treatments in a Petri dish. The pot experiment also showed that the inoculation of D5A increased root biomass by up to $73 \%$ and RA by up to $100 \%$ and TPH removal efficiencies by $16 \%$ in the petroleum-contaminated saline-alkaline soil.

\section{Conclusion}

In this study, a total of 115 PGPR were isolated from the rhizosphere of tall fescue grown in the petroleum-contaminated salinealkali soils. Among them, the isolate D5A showed the highest PGP activities and growth-promoting ability. It also had a good adaptability to extreme $\mathrm{pH}$ and high salinity and alkalinity levels. The D5A was identified as Klebsiella sp. The inoculation of this isolate enhanced the phytoremediation efficiency by further $16 \%$ and also promoted the growth of host plants in the petroleum-contaminated saline-alkaline soil. Thus, the D5A can be used as a potential inoculum to improve phytoremediation of the organic contaminants in petroleum-contaminated saline-alkaline soils.

\section{Acknowledgements}

We thank Jiangsu Provincial Natural Science Foundation of China (BK2012891), National High Technology Research and Development Program of China (863 Program) (2012AA06A204) and the National Natural Science Foundation of China (41001182) for financial support. 


\section{References}

Ashraf, M., Berge, S.H., Mahmood, O.T., 2004. Inoculating wheat seedling with exopolysaccharide-producing bacteria restricts sodium uptake and stimulates plant growth under salt stress. Biol. Fertil. Soils 40, 157-162.

Bal, H.B., Nayak, L., Das, S., Adhya, T.K., 2013. Isolation of ACC deaminase producing PGPR from rice rhizosphere and evaluating their plant growth promoting activity under salt stress. Plant Soil 366, 93-105.

Clemensson-Lindell, A., 1994. Triphenyltetrazolium chloride as an indicator of fineroot vitality and environmental stress in coniferous forest stands: applications and limitations. Plant Soil 159, 297-300.

Gerhardt, K.E., Huang, X.D., Glick, B.R., Greenberg, B.M., 2009. Phytoremediation and rhizoremediation of organic soil contaminants: potential and challenges. Plant Sci. 176, 20-30.

Glick, B.R., 1995. The enhancement of plant growth by free living bacteria. Can. J. Microbiol. 41, 109-117.

Glick, B.R., Stearns, J.C., 2011. Making phytoremediation work better: maximizing a plant's growth potential in the midst of adversity. Int. J. Phytorem. 13 (sup1), 416.

Glick, B.R., Liu, C.P., Ghosh, S., Dumbroff, E.B., 1997. Early development of canola seedlings in the presence of the plant growth-promoting rhizobacterium Pseudomonas putida GR12-2. Soil Biol. Biochem. 29, 1233-1239.

Glickmann, E., Dessaux, Y., 1995. A critical-examination of the specificity of the salkowski reagent for indolic compounds produced by phytopathogenic bacteria. Appl. Environ. Microbiol. 61, 793-796.

Gurska, J., Wang, W., Gerhardt, K.E., Khalid, A.M., Isherwood, D.M., Huang, X.D. Glick, B.R., Greenberg, B.M., 2009. Field test of a multi-process phytoremediation system at a petroleum sludge contaminated land farm. Environ. Sci. Technol. 43, 4472-4479.

Huang, X.D., El-Alawi, Y., Gurska, J., Glick, B.R., Greenberg, B.M., 2005. A multiprocess phytoremediation system for decontamination of persistent total petroleum hydrocarbons (TPHs) from soils. Appl. Environ. Microbiol. 81, 139147.

Lee, S.C., Kim, S.H., Park, I.H., Chung, S.Y., Chandra, M.S., Yong, L.C., 2010. Isolation, purification, and characterization of novel fengycin $S$ from Bacillus amyloliquefaciens LSC04 degrading-crude oil. Biotechnol. Bioprocess Eng. 15, $246-253$.

Liu, W.X., Luo, Y.M., Teng, Y., 2010a. Phytoremediation of oilfield sludge after prepared bed bioremediation treatment. Int. J. Phytorem. 12, 268-278.
Liu, W.X., Luo, Y.M., Teng, Y., Zhengao Li, ZG., Ma, L.Q., 2010b. Bioremediation of oily sludge-contaminated soil by stimulating indigenous microbes. Environ. Geochem. Health 32, 23-29.

Liu, W.X., Sun, J.Y., Ding, L.L., Luo, Y.M., Chen, M.F., Tang, C.X., 2013. Rhizobacteria (Pseudomonas sp. SB) assist phytoremediation of oily-sludge-contaminated soil by tall fescue (Testuca arundinacea L.). Plant Soil 371, 533-542.

Lu, R.K., 1999. Analytical Methods of Soil Agricultural Chemistry. China Agric Sci Techno Press, Beijing (in Chinese).

Lu, Z.Q., Liu, D.L., Liu, S.K., 2010. Elevated salt tolerance in Transgenic tobacco plants expressing cytosolic ascorbate peroxidase genes from rice (Oryza sativa L.). Bull. Bot. Res. 4, 448-454 (in Chinese).

Mohsen, S., Majid, A. Mohammad, A., Hajabbasi, F. N., Mohammad, R.S., Jan, H.C., 2010. Phytoremediation of an aged petroleum contaminated soil using entophyte infected and non-infected grasses. Chemosphere 81, 1084-1090.

Moran, R., Porath, D., 1980. Chlorophyll determination in intact tissues using N,Ndimethylformamide. Plant Physiol. 65, 478-479.

Payne, S.M., 1994. Detection, isolation, and characterization of siderophores. Methods Enzymol. 235, 329-344.

Penrose, D.M. Glick, B.R., 2003. Methods for isolating and characterizing ACC deaminase-containing plant growth-promoting rhizobacteria. Physiol. Plant. $118,10-15$.

Qadir, M., Schubert, S., 2002. Degradation processes and nutrient constraints in sodic soils. Land Degrad. Dev. 13, 275-294.

Shrivastava, U.P., 2013. Isolation and initial characterization of diazotrophic plant growth promoting rhizobacteria (PGPR) from rice rhizosphere of Parsa and Bara district of Nepal. Int. J. Pharm. Life Sci. 4, 2481-2488.

Sumia, K., Muhammad, A., Samina, L., Qaiser, M.K., 2013. Plant-bacteria partnerships for the remediation of hydrocarbon contaminated soils. Chemosphere 90, 1317-1332.

Sundara-Rao, W., Sinha, M., 1963. Phosphate dissolving microorganisms in the soil and rhizosphere. Indian J. Agric. Sci. 33, 272-278.

Vorob'eva, L.A., Pankova, E.I., 2008. Saline-alkali soils of Russia. Eurasian Soil Sci. 41, 457-470.

Wolicka, D., Suszek, A., Borkowski, A., Bielecka, A., 2009. Application of aerobic microorganisms in bioremediation in situ of soil contaminated by petroleum products. Bioresour. Technol. 100, 3221-3227.

Yang, H.J., Li, W.X., Luo, Y.M., Huang, Y.J., Sun, J.Y., Xu, X.S., 2014. The sectional determination of extractable total petroleum hydrocarbons in soil by gas chromatography-mass spectrometry. Soils 46, 134-138 (in Chinese). 